Chapman University

Chapman University Digital Commons

Sociology Faculty Articles and Research

Sociology

$1-19-2015$

\title{
The Moderating Effect of Self-Efficacy on Normal- Weight, Overweight, and Obese Children's Math Achievement: A longitudinal Analysis
}

Ashley Wendell Kranjac

Chapman University, kranjac@chapman.edu

Follow this and additional works at: https://digitalcommons.chapman.edu/sociology_articles

Part of the Educational Sociology Commons, Medicine and Health Commons, and the Science and Mathematics Education Commons

\section{Recommended Citation}

Kranjac AW. The moderating effect of self-efficacy on normal-weight, overweight, and obese children's math achievement: A longitudinal analysis. Social Science \& Medicine 2015; 128: 168-177. doi: 10.1016/j.socscimed.2015.01.007

This Article is brought to you for free and open access by the Sociology at Chapman University Digital Commons. It has been accepted for inclusion in Sociology Faculty Articles and Research by an authorized administrator of Chapman University Digital Commons. For more information, please contact laughtin@chapman.edu. 


\section{The Moderating Effect of Self-Efficacy on Normal-Weight, Overweight, and Obese Children's Math Achievement: A longitudinal Analysis}

\section{Comments}

NOTICE: this is the author's version of a work that was accepted for publication in Social Science \& Medicine. Changes resulting from the publishing process, such as peer review, editing, corrections, structural formatting, and other quality control mechanisms may not be reflected in this document. Changes may have been made to this work since it was submitted for publication. A definitive version was subsequently published in Social Science \& Medicine, volume 128, in 2015. DOI: 10.1016/j.socscimed.2015.01.007

The Creative Commons license below applies only to this version of the article.

\section{Creative Commons License}

\section{(c) (1)(2)}

This work is licensed under a Creative Commons Attribution-Noncommercial-Share Alike 4.0 License.

\section{Copyright}

Elsevier 
Self-efficacy, Weight, and Children's Math Achievement

\section{THE MODERATING EFFECT OF SELF-EFFICACY ON NORMAL-WEIGHT, OVERWEIGHT, AND OBESE CHILDREN'S MATH ACHIEVEMENT: \\ A LONGITUDINAL ANALYSIS}

Abstract Word Count: 165

Total main text word count: 8,366

Number of tables: 5

Number of figures: 1

Number of equations: 4

Keywords: Childhood obesity, self-efficacy, quantitative, health 
Self-efficacy, Weight, and Children’s Math Achievement

\begin{abstract}
Increased body weight is associated with decreased cognitive function in school-aged children. The role of self-efficacy in shaping the connection between children's educational achievement and obesity-related comorbidities has not been examined to date. Evidence of the predictive ability of self-efficacy in children is demonstrated in cognitive tasks, including math achievement scores. This study examined the relationship between self-efficacy and math achievement in normal weight, overweight, and obese children. I hypothesized that overweight and obese children with higher self-efficacy will be less affected in math achievement than otherwise comparable children with lower self-efficacy. I tested this prediction with multilevel growth modeling techniques using the ECLS-K 1998-1999 survey data, a nationally representative sample of children. Increased self-efficacy moderates the link between body weight and children's math achievement by buffering the risks that increased weight status poses to children’s cognitive function. My findings indicate that self-efficacy moderates math outcomes in overweight, but not obese, children.
\end{abstract}


Self-efficacy, Weight, and Children’s Math Achievement

\section{THE MODERATING EFFECT OF SELF-EFFICACY ON NORMAL-WEIGHT, OVERWEIGHT, AND OBESE CHILDREN'S MATH ACHIEVEMENT: A LONGITUDINAL ANALYSIS}

The number of American children classified as obese has sharply risen in recent years (Ogden et al. 2014; Wang and Beydoun 2007). Approximately 17\% of children aged 2 to 19 years-old are classified as obese [i.e., have a body mass index (BMI) above $30 \mathrm{~kg} \mathrm{~m}^{-2}$; (Ogden et al. 2014)]. There are, however, large disparities in childhood obesity prevalence between racial and ethnic minority groups, and by geographic location, with the highest incidence among Hispanic children (Ogden et al. 2014) and in children residing in the southeast region of the United States (Gopal et al. 2010). One population at risk is low-income elementary-aged children (Kopelman 2007), an already vulnerable group whose rates of obesity have steadily increased across all races except Asians/Pacific Islanders, irrespective of gender (Kopelman 2013). Socioeconomic inequality is associated with geographically concentrated childhood obesity among low-income groups that may lead to an accumulation of disadvantage for children throughout their life course (Giskes et al. 2008; Power, Manor, and Matthews 2003; Woolf and Aron 2013, p. 233).

The consequences of poor physiological and psychological health extend to the academic domain. An overweight or obese child may succumb to anxiety and depression as a result of social marginalization and/ or peer discrimination due to the stigma associated with being overweight, and, consequently, her math performance may suffer. For example, overweight and obese adolescents are more socially isolated and have fewer friendships than those of normal weight (Strauss and Pollack 2003). This may then lead to devastating outcomes associated with psychological instability, and, in some cases, lowered academic performance (Robinson 2006). 
Self-efficacy, Weight, and Children’s Math Achievement

Increased body weight is associated with decreased cognitive function in school-aged children (Li, Dai, Jackson, and Zhang 2008). Researchers have shown that overweight and obesity in children is associated with deficits in executive function, which relies on proper functioning of the part of the brain responsible for planning and judgment (Cserjesi. Luminet, Molnar, and Lenard 2007; Braet, Claus, Verbeken, and Vlierghe 2007). Poor math performance, for example, could be due to ineffective planning or the inability to shift from one mental state to another, update working memory, or inhibit impulsive behavior (St Clair-Thompson and Gathercole 2006). Given that the pathophysiological process of weight-associated complications culminates in cognitive decline and is driven by neural, cardiovascular, endocrine, musculoskeletal, renal, gastrointestinal, and pulmonary system malfunction, in addition to psychosocial problems (Kamijo et al. 2014; Garver et al. 2013), childhood obesity trends have implications for children's well-being in both the short and long term, including academic outcomes (Daniels et al. 2005; Freedman et al. 2007; see Taras and Potts-Datema 2009, for review). Importantly, academic outcomes are not driven solely by cognitive capacity (Bandura 1993), a limited pool of energy, resources, or fuel by which some cognitive processes are mobilized and maintained (Johnson and Heinz, 1978, p.422). Psychological resources such as optimism, personal control and a sense of meaning are protective for mental health (Frankl 1963; Taylor, 1989; Seligman 1998; Taylor et al. 2000), and these learned behaviors also assist children in educational achievement (Kolb 1984; Zimmerman 1989; Casey et al. 2005). Among these psychological resources, self-efficacy—typically conceptualized as perceived judgments of one’s capabilities to organize and execute courses of action to attain chosen goals (Bandura 1977) — has consequences for children’s psychological development, educational outcomes, and reproduction of stratification across generations (see Multon et al. 1991 for review; Schunk 
Self-efficacy, Weight, and Children’s Math Achievement

1995; Schunk and Pajares 2004). The role of self-efficacy in shaping the connection between children’s math achievement and obesity-related comorbidities has not been examined to date.

Perceived self-efficacy is the foundation of human motivation (Bandura 1993, 1994, 2006). At the individual level, symbolic processes through which knowledge is formed may be analyzed as contributing to the production of individual differences in development (Dannefer 1984). For example, the expectations communicated to, and interpreted by, a child, contribute to self-definition and to her plan of action. Bandura, and other social psychologists, suggest that individual action is driven by the core belief that we can produce desired results through our behavior. Self-efficacy moderates the effect of gender and prior experience on self-concept and mathematical problem solving (Pajares and Miller 1994). It is also becoming evident that selfefficacy may be an important mechanism in the treatment of obesity (Clark et al. 1991; Linde et al. 2006). In the present study, I examined the relationship between self-efficacy and math achievement in normal weight, overweight, and obese children.

As a measure of cognitive function, I used math achievement, and not literacy, scores from kindergarten to eighth grade, because past research indicates that stress associated with variations in physical appearance can decrease math performance in adults (Fredrickson et al. 1998; Gable et al. 2012). Also, self-efficacy has been shown to predict math performance for undergraduate college students (Siegel et al. 1985). I hypothesized that children with consistently heightened BMI scores will have lower math achievement, compared to those of children with lower BMI (Gable et al. 2012).

Further, self-efficacy has previously been shown to serve as a moderator of weight management (Bandura 2000), life stressors (Bandura 1994), and scholastic aptitude (Brown et al. 1989). Because self-efficacy engenders a wide range of capacities and skills that children may 
Self-efficacy, Weight, and Children’s Math Achievement

draw upon to support their math achievement - and potentially buffer the effects of increased weight on learning-I expected self-efficacy to factor into this linkage by moderating the extent to which children’s increased weight status will affect their math achievement. Thus, I hypothesized that, compared to overweight and obese children with lower self-efficacy, those who are overweight and obese but have higher self-efficacy, would score better on math achievement assessments. I tested these hypotheses by applying multilevel growth modeling techniques (Singer and Willet 2003) to data from the Early Childhood Longitudinal StudyKindergarten class 1998-1999 (ECLS-K).

\section{BACKGROUND}

\section{LINKING OBESITY AND MATH ACHIEVEMENT TO SELF-EFFICACY}

Early childhood health influences later life outcomes (Currie 2009; Almond and Currie 2010, 2011). The current study is predicated on the notion that weight-related comorbidities are associated with cognitive dysfunction. The negative association between obesity and cognitive function is well documented (Li et al. 2008; Shore et al. 2008; McLaren 2007), as is the positive association between self-efficacy and academic outcomes (Zimmerman 2000; Cowen et al. 1991; Bandura 1997). However, the direct association between self-efficacy and math outcomes among normal weight, overweight, and obese children in the United States has never been examined.

There is no consensus on the causal effect of childhood obesity on standardized test scores and academic outcomes. Cross-sectional and longitudinal studies examining the association between academic achievement and obesity are inconsistent. Researchers have found no association (Kaetner et al. 2009), a negative association (Averett and Stifel 2010), a mediation between obesity and self-esteem (Tershakovec et al. 1994), obesity and externalizing 
Self-efficacy, Weight, and Children’s Math Achievement

behavioral problems (Crosnoe 2007), and obesity and interpersonal skills (Klinitzke et al. 2013)

in poor academic performance. Nonetheless, there is ample theoretical and empirical evidence

indicating a likely connection. Thus, my conceptual model is that overweight and obesity in

children affects cognitive function and is linked to learning, which in turn affects math academic outcomes.

Self-efficacy has emerged as an effective predictor of students’ motivation and scholarship. Self-efficacious students contribute more in the classroom, work more assiduously, persevere longer, and have fewer disadvantageous reactions when faced with challenges (Bandura 1997). Furthermore, measures of self-efficacy are highly correlated with achievement in academic work and persistence (Zimmerman 2000). Evidence of the predictive ability of selfefficacy in children is demonstrated in cognitive tasks, including math performance (Cowen et al. 1991). For example, Schnuck et al. (1985) found a positive association between perceived self-efficacy and rate of accurate arithmetic solutions. Thus, research to date clearly links selfefficacy and math achievement (Bandura 1997; Shnuck et al. 1985; Pajares and Kranzler 1995; Adeyinka et al. 2007). Increased self-efficacy may, then, condition the link between overweight or obesity and children's achievement by buffering (or minimizing) the risks that increased weight status poses to children’s math performance.

\section{DATA AND METHODS}

\section{Data and Sample}

Analyses are based on the Early Childhood Longitudinal Study_Kindergarten class 1998-1999 (ECLS-K), a nationally representative sample of 21,260 children from kindergarten to eighth grade, conducted by the U.S. Department of Education, National Center for Education Statistics (NCES), and designed to study the development of educational stratification among 
Self-efficacy, Weight, and Children's Math Achievement

American school children (West, Denton, and Reaney 2000). Participants were selected using a multi-stage sampling design. For a more detailed description of the ECLS-K study design see, Tourangeau et al. (2009).

\section{Inclusion Criteria}

Because “missingness” increased over time due to attrition in the ECLS-K data, I estimated my models using full information maximum-likelihood method (FIML), which uses data from all observations in the data set. The FIML estimation method assumes data are missing at random (MAR), wherein the conditional covariates are not associated with the propensity for missing data on the outcome measure (i.e., math achievement). This approach maximizes the statistical power for differentiating between math developmental trajectories of children with missing data on the outcome at any wave. The final sample size was 5,034. I used multiple imputation to impute missing values for children who participated in a wave but did not provide a response for a specific independent variable. This method resulted in multiple complete data sets (Allison 2001). I imputed data using the MIM command, a multivariate imputation program in Stata 13.0 (Carlin, Golati, and Royston 2008). I averaged empirical results across ten imputation samples (Rubin 1987). The estimates presented here are statistically similar to findings from analyses where I handled missing data for the independent variables using listwise deletion, indicating that estimates are robust across different missing data specifications. All multivariate analyses were conducted using HLM 7.01.

At enrollment (kindergarten fall, T1), children (51\% female) were identified by parents as 71\% White, 5\% African American, 15\% Hispanic, 5\% Asian, and 5\% Other Race. In the analyses, ECLS-K data were weighted to account for the multistage probability sampling that oversampled Asians and Pacific Islanders. Weights are provided in the ECLS-K for cross- 
Self-efficacy, Weight, and Children’s Math Achievement

sectional and longitudinal data analyses; weights were computed for children with complete data on the data points under investigation. Normalized child-level weights were used to produce representative estimates of the 1998-1999 kindergarten population of children.

\section{MEASURES}

\section{Time}

A variable based on average age at each direct assessment was created to represent time, as shown in Table 1. Time 1 (T1), kindergarten fall, is considered the baseline. At T1, average age was $5.71(\mathrm{SD}=0.36)$ years. At $\mathrm{T} 2$, kindergarten spring, average age was 6.23 years ( $\mathrm{SD}=0.36$ ), indicating the passage of about 6 months between $\mathrm{T} 1$ and $\mathrm{T} 2$. Beginning at $\mathrm{T} 3$, the time unit is defined in years, and children are about one year older, with an average age of 6.67 years $(S D=0.38)$. At $T 4$, average age was 7.24 years $(S D=0.35)$. At $T 5$, average age was 9.13 years $(S D=0.35)$. At $T 6$, average age was 11.07 years $(S D=0.36)$. At $T 7$, average age was 14.07 years $(\mathrm{SD}=0.35)$.

\section{Weight Status}

ECLS-K staff assessed children’s height and weight during each assessment by using a portable digital scale and stadiometer (Shorr Products, Olney, Maryland). Both weight and height measurements were recorded twice, and the average of the two measures was used in the present analyses. The overall average unweighted BMI score was 18.36, with a standard deviation of 4.53. Table 1 displays the unweighted means and standard deviations for BMI scores by gender and wave.

Using the 2000 Center for Disease Control Growth Charts: United States (Kuczmarski et al. 2002), I created a categorical variable based on BMI (weight $\left[\mathrm{kg} / \mathrm{height}[\mathrm{m}]^{2}\right.$ ), and classified children as underweight ( $<5^{\text {th }}$ percentile), normal weight $\left(>5^{\text {th }}\right.$ percentile and $<85^{\text {th }}$ percentile), 
Self-efficacy, Weight, and Children’s Math Achievement

overweight $\left(>85^{\text {th }}\right.$ percentile to $<95^{\text {th }}$ percentile), or obese $\left(\geq 95^{\text {th }}\right.$ percentile). I subsequently combined underweight and normal-weight categories into a single category due to the small

number of underweight children across all time points (0.02; $\mathrm{SD}=0.12)$. Overall, $58 \%(\mathrm{SD}=0.49)$ of male and $64 \%(\mathrm{SD}=0.48)$ of female children were normal-weight. $21 \%(\mathrm{SD}=0.21)$ of male and $21 \%(S D=0.41)$ of female children were classified as overweight. And, $21 \%(S D=0.21)$ of male and 15\% (SD=0.36) of female children were classified as obese. Weight status was included in my analytic model in several different ways. Dummy variables indicating a child’s weight status category and a continuous measure of BMI were both included to imply that the added decrement to children's math achievement that accrued for an additional point in BMI further decreased math achievement if the child moved from the normal weight to the overweight or from the overweight to the obese category.

\section{Self-Efficacy}

An adaptation of the Self-Description Questionnaire (SDQ) II and The Self-Concept and Locus of Control scales from the National Educational Study of 1988 (NELS:88) were administered during the eighth grade assessment session to ascertain children's socioemotional development. Thirteen statements measuring children’s self-perceptions and amount of control they possessed throughout their life were used to assess locus of control. Children scored the items on a continuum from "strongly agree” to "strongly disagree” for each item; values ranged from -1.53 to 2.50 , with higher scores indicating greater perception of control throughout their life. I dichotomized the locus of control measure into low and high levels of self-efficacy, with negative and positive values representing low and high levels of self efficacy, respectively. It is well documented that locus of control and generalized self-efficacy are indicators of the same 
Self-efficacy, Weight, and Children's Math Achievement

higher order concept (Judge et al. 2002; Adeyinka et al. 2011). Internal consistency of the locus of control measure is moderate at the Cronbach Alpha level of 0.68 (Tourangeau et al. 2009).

\section{Math Achievement}

At each assessment period, children were evaluated in a 50-minute to 70-minute session in kindergarten and $1^{\text {st }}$ grade, and in a 90 -minute session in $3^{\text {rd }}, 5^{\text {th }}$, and $8^{\text {th }}$ grade. The assessment was developed specifically for the ECLS-K, and children were tested on previously used instruments (Woodcock-McGrew-Werder 1996).

The ECLS-K math assessment focused on age-appropriate mathematical knowledge and skills such as knowledge of numbers and shapes, relative size, ordinality and sequence, addition and subtraction, multiplication and division, place value, rate and measurement, fractions, and area and volume (Tourangeau et al. 2009, pp 2-10). The assessments yielded number right scores, standardized scores, and latent trait scores from item response theory (IRT). I used IRT scores because this assessment placed children's ability on a continuous scale by using the pattern of right, wrong, and omitted responses, and the pattern of difficulty, discriminating ability, and ability to correctly guess each item. Thus, the measure produced a score based on the items a child would have answered correctly if all the questions were answered for that particular assessment. Reliability math scores were high at Cronbach Alpha levels ranging from 0.89 to 0.94 (Tourangeau et al. 2009).

\section{Covariates}

Time-variant and time-invariant measures were included in the final models. Timevarying measure includes age in years and BMI. Age is centered on the earliest time children normally begin kindergarten (i.e., 5 years of age). $B M I$ is a continuous measure of body mass index. BMI categories are indicator variables representing the child's BMI percentile 
Self-efficacy, Weight, and Children's Math Achievement

classification at each time period, and includes normal weight, overweight, and obese, with

normal weight as the reference. Time invariant covariates that were included represent child and family characteristics. Race is an indicator variable representing race and ethnicity, and is categorized as White, African American, Hispanic, Asian, and Other Race, with White as the reference category. Female is a dichotomous variable indicating whether the child is or is not female. The family characteristic included is parent's education level. Parent's education level is an indicator variable representing the highest level of education attained by either parent at any assessment period, and was classified as high school dropout, high school graduate, attended some college, college degree holder, and advanced degree holder, with high school dropout as the reference category. I included parent's education level instead of parental income because ample evidence points to parental education as a stronger indicator of child's achievement (Dubow et al. 2010; see Desforges et al. 2003, for review). In the interaction model, Elementary is a dichotomous variable indicating whether or not the child is in elementary school. Middle is a dichotomous variable indicating whether or not the child is in middle school.

Table 1 about here.

Table 2 about here.

\section{Analytic Strategy}

I estimated the effect of BMI and self-efficacy on math achievement trajectories using multilevel growth curve modeling techniques (Singer and Willet 2003). These models estimated the effect of change in BMI on change in math achievement trajectories, and allowed me to determine whether the changes in developmental trajectories coincide with BMI changes over time, and also to simultaneously determine if there is a moderating effect of self-efficacy. The estimated coefficients for BMI in these models show the change in math achievement trajectory for children who experienced an increase in BMI. All models were estimated using sampling 
Self-efficacy, Weight, and Children's Math Achievement

weights that adjust for the unequal probabilities of selection for children in the ECLS-K. In these models, time points are nested within children.

The level-1 model fits BMI as a function of age across the observations for each child, and the level-2 model fits the level-1 intercepts and coefficients across all individuals as a function of children's fixed characteristics (gender, race / ethnicity, parent's highest education level, and self-efficacy). Exploratory analyses indicated that children's math achievement is most appropriately captured by a quadratic growth function due to the non-linear relationship between math and age. Consequently, I only present estimates from quadratic growth models. Model 1 summarized children's math achievement trajectories between kindergarten and $8^{\text {th }}$ grade; model 2 estimated the effect of increased weight status on children's math achievement net of baseline growth trajectories; model 3 examined whether changes in weight trajectory coincide with changes in children's math achievement scores and simultaneously tests whether self-efficacy acts as a moderator of the hypothesized decline in math achievement; model 4 examined interactions between weight category and age, sex, race, elementary/ middle school, or parent's education level to assess whether their intersection is related to math achievement.

\section{RESULTS}

\section{Model 1. Baseline Growth in Math Achievement}

Level 1

$M a t h_{i t}=\pi_{0 i}+\pi_{1 i} A g e_{i t}+\pi_{2 i} A g e 2+\varepsilon_{i t}$

Level 2

$\pi_{0 i}=\gamma_{00}+\delta_{0 i}$

$\pi_{1 i}=\gamma_{10}+\delta_{0 i}$

$\pi_{2 i}=\gamma_{20}+\delta_{2 i}$

$\pi_{0 i}$ represents the estimated math score for a child who is five years of age and of normal weight $\pi_{1 i}$ represents the linear growth component for mathematics between kindergarten and 
Self-efficacy, Weight, and Children’s Math Achievement

eighth grade assessments, $\pi_{2 i}$ represents the quadratic growth component of the math

achievement slope, $\varepsilon_{i t}$ is a within child error term, $\delta_{0 i}$ represents random error term for the math achievement intercept, $\delta_{1 i}$ represents the random error term for the linear component of the math achievement slope, $\delta_{2 i}$ represents the error term for the quadratic component of the math achievement slope.

\section{Table 3 about here.}

\section{Estimates and Interpretation}

Model 1 estimates of the fixed and random effects are displayed in Table 3. The estimated coefficients for the fixed effects indicate that children's learning rates increase during early middle childhood and level off during late middle childhood (see the upper portion of Table 3). At age 5, the estimated mean math score for children is 17.19 . Between the ages of 5 and 9, the average child's math score rapidly increases, evidenced by the large positive values for the liner component of the age slope for math (29.87) and the negative value for the quadratic component of the age slope for math (1.61). However, the rate of increase begins to slow by age 9, whereas by age 11 , improvements in mathematics are much more modest than in early middle childhood.

The random effects indicate that patterns of growth vary significantly among children (see the lower portion of Table 3). Both initial levels of math achievement $\left(\chi^{2}=10,257, p<\right.$ $0.001)$ and the linear $\left(\chi^{2}=7,217, \mathrm{p}<0.001\right)$ and quadratic components $\left(\chi^{2}=5,692, \mathrm{p}<0.001\right)$ of growth vary among children. Ranging from 0.27 for the quadratic components of the learning curves, to 0.36 for the linear component of the curve, estimated reliabilities for the math intercepts and linear and quadratic age slope components are, however, relatively low. 
Self-efficacy, Weight, and Children’s Math Achievement

\section{Model 2. Effects of Weight Status}

Mean unconditional math achievement trajectories for 5 year-old sampled children were captured in the baseline model. In this next set of models, I examined the effect of changes in BMI on math achievement, with the added complexity of allowing an additional effect of children crossing into one of the weight status categories (i.e., overweight, obese). I included both dummy variables indicating a child's weight status category and a continuous measure of BMI because I hypothesized that the effect of BMI on math achievement is a complex non-linear function in which each one-point increase in BMI lowers children's math achievement, but that moving from the normal weight to the overweight or from the overweight to the obese category potentially leads to an additional reduction in math achievement.

\section{Specification.}

I estimated the effects of weight on children's development trajectories by including three covariates representing the continuous measure of BMI and categorical measures of BMI into the level-1 equation. I included both the continuous and discrete measures of BMI not to lose valid variation with discretization (Markon et al. 2011).

Level 1

Math $_{i t}=\pi_{0 i}+\pi_{1 i}$ Age $e_{i t}+\pi_{2 i}$ Age $2+\pi_{3 i} B M I+\pi_{4 i}$ Overweight $+\pi_{5 i}$ Obese $+e$

Level 2

$\pi_{0 i}=\gamma_{00}+\delta_{0 i}$

$\pi_{1 i}=\gamma_{10}+\delta_{0 i}$

$\pi_{2 i}=\gamma_{20}+\delta_{2 i}$

$\pi_{3 i}=\gamma_{30}+\delta_{3 i}$

$\pi_{4 i}=\gamma_{40}+\delta_{4 i}$

$\pi_{5 i}=\gamma_{50}+\delta_{5 i}$

At level $1, \pi_{0 i}$ represents the estimated math score for a child in the normal- weight category when age, overweight, and obese are 0 . The interpretation of $\pi_{1 i}$ and $\pi_{2 i}$ changes somewhat in this model; $\pi_{1 i}$ and $\pi_{2 i}$ represent the linear and quadratic components of growth 
Self-efficacy, Weight, and Children's Math Achievement

controlling for weight status. $\pi_{3 i}, \pi_{4 i}$, and $\pi_{5 i}$ now represent, respectively, the effect of BMI increasing, being classified as overweight or obese, while controlling for baseline growth trajectories. If $\pi_{3 i}$ is negative, every point increase in BMI beyond normal weight gain tends to coincide with slower learning rates. If $\pi_{4 i}$ or $\pi_{5 i}$ is negative, overweight and obesity tend to coincide with a decline in children’s learning rates independent of the linear BMI variable.

\section{Estimates and Interpretation}

\section{Table 4 about here.}

The estimated coefficients from this model are displayed in Table 4. The timeindependent effects of overweight and obesity on children’s development are negative. On average, every point increase in BMI beyond normal weight gain is associated with a decline of 0.0001 in children's math achievement trajectory ( $\mathrm{p}<0.001)$. When a child is overweight, on average, their math achievement score is 5.77 points lower than we would expect if she was normal-weight at 5 years-old ( $p<0.001)$, and 7.97 points lower if she was obese $(\mathrm{p}<0.001)$. Given that math achievement rates increase by about 29 points annually, over most of the period, a 5.77 and 7.97 point reduction in math scores is comparable to 2 and 3 months of math learning, respectively.

As shown in the lower portion of Table 4, the random effects estimates indicate that the effect of gaining weight on children's math trajectories varies significantly among children classified as overweight $\left(\right.$ var. $\left.=0.33, \chi^{2}=488.2, \mathrm{p}=0.03\right)$ or obese $\left(\right.$ var. $0.21, \chi^{2}=453.6, \mathrm{p}=$ 0.02). The effect of increased BMI also varies significantly among children (var. $0.25, \chi^{2}=$ 485.7, $\mathrm{p}=0.01$ ). The reliability is low for all measures; 0.066, 0.017, and 0.032, respectively. Much of the variability among children in the effects of weight status on math achievement is 
Self-efficacy, Weight, and Children's Math Achievement

due to sampling variability that cannot be explained by child characteristics, resulting in low reliabilities for these coefficients.

\section{Figure 1 about here.}

\section{Model 3. Self-efficacy as Potential Moderator}

In this model, I tested my second hypothesis by examining how children's level of selfefficacy influences the estimated effect of weight status on math achievement. I included indicators of children's sex, race, and parental education level as controls at level 2 because of the well-documented association between these characteristics and children's math achievement, and their potential association with children's self-efficacy. Self-efficacy is also included at level 2 as a dichotomous variable indicating whether the child scored high or low in self-efficacy.

Because I was primarily interested in how self-efficacy affects math achievement scores in children of varying weight statuses, I allowed only BMI, overweight, and obesity to vary as a function of self-efficacy. Level 1 is the same as the previous model.

Level 1

$$
\text { Math }_{i t}=\pi_{0 i}+\pi_{1 i} \text { Age } e_{i t}+\pi_{2 i} \text { Age } 2+\pi_{3 i} \text { BMI }+\pi_{4 i} \text { Overweight }+\pi_{5 i} \text { Obese }+e
$$

Level 2

Child Characteristics

$$
\begin{aligned}
\pi_{1 i} & =\gamma_{10}+\gamma_{11} \text { Parent education } \\
\pi_{2 i} & =\gamma_{20}+\gamma_{21} \text { Parent education } \\
\pi_{3 i} & =\gamma_{30}+\gamma_{31} \text { Parent education }+_{32} \text { High Self }- \text { efficacy } \\
\pi_{4 i} & =\gamma_{40}+\gamma_{41} \text { Parent education }+\gamma_{42} \text { High Self }- \text { efficacy } \\
\pi_{5 i} & =\gamma_{50}+\gamma_{51} \text { Parent education }+\gamma_{52} \text { High Self }- \text { efficacy }
\end{aligned}
$$

$\pi_{70 i}=\gamma_{60}+\gamma_{61}$ (Male)

$+\gamma_{62}$ (African American)

$+\gamma_{63}$ (Latino)

$+\gamma_{64}$ (Asian)

$+\gamma_{65}$ (Other)

Because seven waves of data do not provide sufficient statistical power to reliably estimate the time-varying random effects of weight status, I do not allow the weight effects in this model to randomly vary. At level $1, \pi_{0 i}$ still represents the estimated math score for a five- 
Self-efficacy, Weight, and Children's Math Achievement

year old child in the normal-weight category. $\pi_{1 i}$ and $\pi_{2 i}$ represent the linear and quadratic components of growth controlling for BMI and BMI categories, respectively. $\pi_{3 i}, \pi_{4 i}$, and $\pi_{5 i}$ now represent the effect of BMI, overweight, and obesity controlling for baseline growth trajectories. $\gamma_{11}, \gamma_{21}, \gamma_{31}, \gamma_{41}, \gamma_{51}$ indicate how the effects of BMI, overweight, and obesity differ by parental education level. $\gamma_{32}, \gamma_{42}, \gamma_{52}$ reveal how the effects of being overweight or obese differ by self-efficacy in children's math achievement. $\gamma_{61}$ indicates how the effects of overweight and obesity differ by gender. $\gamma_{62}, \gamma_{63}, \gamma_{64}, \gamma_{65}$ indicate how the effects of increased weight differs for racial and ethnic minority children from white children. In this model, if $\gamma_{32}, \gamma_{42}$, or $\gamma_{52}$ are positive and significant, overweight and obese children's math achievement trajectories will benefit from higher levels of self-efficacy.

Table 5 about here.

\section{Estimates and Interpretation.}

The estimates in Table 5 for this model show that the effects of overweight and obesity vary significantly among children. Partly consistent with hypothesis 2 , overweight children's math achievement trajectories benefit with high levels of self-efficacy. On average, the math trajectories of overweight children with high levels of self-efficacy increase by 3.62 points more than those of overweight children with low levels of self-efficacy $(\mathrm{p}<0.005)$. High self-efficacy, by contrast, is not significantly associated with improved math achievement trajectories in obese children $(\mathrm{p}=0.73)$. I calculated and graphed predicted probabilities of math achievement by age and self-efficacy level by weight status (Figure 1).

\section{Figure 1 about here.}

Racial and ethnic minority children differ significantly from white children in math achievement. African American children’s BMI effects on achievement, on average, are 0.00006 
Self-efficacy, Weight, and Children's Math Achievement

more negative $(\mathrm{p}<0.01)$ than those of white children. Hispanic children BMI effects are also more negative than those of white children by about 0.00001 points, on average $(\mathrm{p}=0.02)$. Female children have a 0.00002 more negative BMI effects on math achievement compared to male children ( $\mathrm{p}<0.001)$. Overweight racial and ethnic minority children do not differ significantly from overweight white children in math achievement. Other Race children classified as obese have math achievement scores that are 7.89 points lower than those of obese white children ( $p=0.02)$. The estimated effect of being overweight differs significantly from normal-weight children based on parental education level. For overweight children whose parents have attended some college, math achievement scores are 1.84 points lower than those of overweight children whose parent's dropped out of high school $(\mathrm{p}=0.03)$. Children who are classified as overweight and have a parent who is a college graduate are 8.23 points higher than overweight children whose parents have dropped out of high school $(p=0.03)$. Overweight children, on average, who have a parent that received an advanced degree are 9.13 points higher than overweight children whose parents dropped out of high school $(\mathrm{p}<0.005)$. Scores for children classified as obese, by contrast, are not significantly associated with the expected benefits of parental education level from math achievement.

\section{Model 4. Interaction Effects}

To test whether the intersection between weight category and age, sex, race, elementary school, middle school, or parent's education level is related to math achievement, I incorporated multiplicative terms into model 2 . At level $1, \pi_{0 i}$ represents the estimated math score for a child in the normal- weight category when age, overweight, and obese are $0 . \pi_{1 i}$ and $\pi_{2 i}$ represent the linear and quadratic components of growth controlling for weight status. $\pi_{3 i}, \pi_{4 i}$, and $\pi_{5 i}$ now represent, respectively, the effect of BMI increasing, being classified as overweight or obese, 
Self-efficacy, Weight, and Children’s Math Achievement

while controlling for baseline growth trajectories. $\pi_{6 i}, \pi_{7 i}, \pi_{8 i}$ represent the interaction effects of age (shown below), sex, race, elementary school, middle school, or parent's education level on, respectively, increasing BMI, being classified as overweight, or as obese.

Level 1

$$
\begin{aligned}
\text { Math }_{i t} & =\pi_{0 i}+\pi_{1 i} \text { Age } e_{i t}+\pi_{2 i} \text { Age } 2+\pi_{3 i} \text { BMI }+\pi_{4 i} \text { Overweight }+\pi_{5 i} \text { Obese }+\pi_{6 i} \text { Age } * \text { Overweight }+\pi_{7 i} \text { Age } \\
& * \text { Obese }+\pi_{8 i} \text { Age } * B M I+e
\end{aligned}
$$

Level 2

$\pi_{0 i}=\gamma_{00}+\delta_{0 i}$

$\pi_{1 i}=\gamma_{10}+\delta_{0 i}$

$\pi_{2 i}=\gamma_{20}+\delta_{2 i}$

$\pi_{3 i}=\gamma_{30}+\delta_{3 i}$

$\pi_{4 i}=\gamma_{40}+\delta_{4 i}$

$\pi_{5 i}=\gamma_{50}+\delta_{5 i}$

$\pi_{6 i}=\gamma_{60}+\delta_{6 i}$

$\pi_{7 i}=\gamma_{70}+\delta_{7 i}$

$\pi_{8 i}=\gamma_{80}+\delta_{8 i}$

Significant interaction between obesity and age $(\mathrm{p}=0.002)$ indicates that the impact of obesity on math achievement is stronger as children age. In contrast, I found no significant differences between overweight and gender $(p=0.21)$ or obesity and gender $(p=0.46)$.

There were no significant differences between overweight and being an African American ( $p=0.49)$, Hispanic $(p=0.85)$, Asian $(p=0.46)$, or Other Race $(p=0.44)$ child or obesity and African American ( $p=0.81)$, Hispanic $(\mathrm{p}=0.13)$, Asian $(\mathrm{p}=0.13)$, or Other Race ( $=0.69)$ child. There were also no significant differences between children in elementary school and overweight $(\mathrm{p}=0.10)$ or obesity $(\mathrm{p}=0.08)$. There were no significant differences between middle school and overweight $(0.09)$ or obesity $(\mathrm{p}=0.12)$. I found no significant differences between overweight and parent's education level for high school graduates $(p=0.23)$, some college $(p=0.38)$, bachelor's degree holders $(p=0.78)$, or advanced degree holders $(p=0.09)$. I also found no difference between obesity and parent's education level for high school graduates 
Self-efficacy, Weight, and Children's Math Achievement

$(p=0.49)$, some college $(p=0.38)$, bachelor's degree holders $(p=0.72)$, or advanced degree holders $(\mathrm{p}=0.31)$.

\section{DISCUSSION}

The increasing number of overweight and obese children in the United States, coupled with the underperformance of our public education system (OECD 2013), warrants a better understanding of the mechanisms contributing to the health of children, as well as the cognitive dysfunction associated with increased weight, particularly in light of declining math achievement in the United States (OECD 2013). Overweight and obese children are more likely to suffer from low self-esteem, anxiety disorders, and other psychopathologies (see Zametkin et al. 2004, for review), which may lead to lowered math performance (Judge and Jahns 2007). However, the causality of this association has yet to be determined. It is possible that mental health problems associated with obesity predispose overweight or obese children to lower academic achievement (Taras and Potts-Datema 2009), or that obesity is a marker, rather than a cause of low achievement (Datar et al. 2004). A strong sense of self-efficacy engenders intrinsic interest and deep-seeded involvement in academic activities (Bandura 1994), and produces a sense of assurance that a child can exercise control over her life.

My findings indicate that, on average, overweight and obesity in children coincides with a few point reduction in math achievement, the equivalent of 2 to 3 months of learning. Overweight children's math achievement trajectories benefit with high levels of self-efficacy, but, in contrast, high self-efficacy does not produce the same effect in obese children. Results further indicate that the effect of obesity on math achievement is stronger as children age, showing that obese children's lowered math scores are lower relative to normal weight children at older ages than at younger ages. The effect of obesity on math achievement may increase as 
Self-efficacy, Weight, and Children’s Math Achievement

children age due to extended periods of institutionalized discrimination and weight-related comorbidities that are progressively more pronounced as children age (Dietz 1998). Thus, in order for self-efficacy to act as a moderator on math achievement trajectories, the onset of obesity is critical. Given that the developmental detriments of overweight on math achievement learning trajectories are moderated by self-efficacy, a learned behavior, intervention timing is crucial.

Why are children most in need of the gains associated with self-efficacy the least likely to benefit? It is possible that the stigma, affective disorders, and social isolation associated with obesity have a stronger impact on obese children, and, thus, may impede the ability of selfefficacy to act as a moderator in the child's math achievement. For example, the stresses associated with overweight are stronger for an obese child due to her higher weight status, and, thus, she may experience more social disadvantages, overwhelming the already more constrained child. In contrast, overweight children may experience less of these social disadvantages as a result of being closer to normal weight children in appearance, and are thus more likely to benefit from self-efficacy as a resource in adapting to the complexities and challenges of heightened BMI. It is also possible that because childhood obesity is stigmatized and obese children are viewed as unhealthy and lazy (Crandall and Schiffhauer 1998; Frisco et al. 2010), these children interpret and internalize the negative communications of others in their construction of self-definition, and lowered math achievement becomes a self-fulfilling prophecy.

Although this is the first study to systematically examine self-efficacy as a moderator of math achievement in overweight and obese children, this study has limitations. First, because of data limitations, self-efficacy was measured at a single time point even though it may fluctuate 
Self-efficacy, Weight, and Children’s Math Achievement

due to varied and varying psychological and physiological factors that were not measured in this data set. For example, differential sensitivity and tolerance to negative peer influences are associated with varying psychological effects, with the most socially connected children being the least negatively affected by their increased weight status (Gable et al. 2012). It has also been shown that weight perceptions have a stronger association with depressive symptoms than actual weight status in adolescents (Frisco et al. 2010). Second, only seven waves of data are available in the ECLS-K 1998-1999 cohort, and therefore, power to identify complex nonlinear relationships between overweight and obesity and child's development is limited. Third, estimated reliabilities for the weight coefficients in the individual-level equations are low. Consequently, the ability to detect significant associations between child characteristics and the estimated effects of overweight and obesity on children's developmental trajectories is attenuated. Fourth, there is no consensus on the causal effect of childhood obesity on standardized test scores and math outcomes, but, there is a clear link between obesity and cognitive function. As such, more research is necessary to find mechanisms underlying cognitive decline associated with overweight and obesity. This knowledge may help elucidate the relationship between increased weight status and lower math achievement in children. Fifth, emphasis of my research is on the "normal" weight status in children, and any interpretation of such an obscure socially constructed and variable pattern is limited in that its contribution is inevitably a by-product of the social reality it describes. Thus, interpretations are always vulnerable to overstating the importance of eventful change and to minimizing the complex continuities of people's lives. Finally, I have focused on child-level attributes as precursors for math outcomes and learning trajectories. I did not, however, consider other relevant factors of 
Self-efficacy, Weight, and Children’s Math Achievement

children's math outcomes such as parent-child and teacher-child relationships or educational context, despite that these factors likely influence children's math achievement and self-efficacy. Despite these limitations, current findings illuminate the importance of psychological resources, particularly self-efficacy, on math achievement trajectories in children. Previous research has shown self-efficacy to act as a moderator across a number of outcomes (Brown et al. 1989; Matsui and Onglatco 1992; Bandura 1994; Bandura 2000; Brown et al. 2001). The current study adds to the self-efficacy literature by showing that self-efficacy acts as a moderator of lowered math achievement in overweight children. Taken together, future research is needed to help improve intervention and treatment programs, and to help implement more effective social policies targeting childhood obesity and related comorbidities, such as lowered math outcomes. 
Self-efficacy, Weight, and Children’s Math Achievement

\section{REFERENCES}

Adeyinka, Tella, Adedeji, Tella, and Adeniyi Sam Olufemi. (2011). Locus of control, interest in schooling and self-efficacy as predictors of academic achievement among junior secondary school students in Osun state, Nigeria, New Horizons in Education 59(1), 2538.

Allison, Paul. (2001). Missing Data. Thousand Oaks, CA: Sage.

Almond D, Currie J. (2010). Human capital development before age five. In The Handbook of Labor Economics, 4b. ed. O Ashenfelter, D Card 15, 1315-486. Amsterdam: Elsevier Science B.V.

Almond D, Currie J. (2011). Killing Me Softly: The Fetal Origins Hypothesis, Journal of Economic Perspective 25(3), 153-72.

Arnstein, P., Caudill, M., Mandle, C. L., Norris, A., \& Beasley, R. (1999). Self efficacy as a mediator of the relationship between pain intensity, disability and depression in chronic pain patients, Pain 80(3), 483-491.

Averett, Susan. L. and David C. Stifel. (2010). Race and gender differences in the cognitive effects of childhood overweight, Applied Economics Letters 17(17), 1673-1679.

Balistreri, Kelly S. and Jennifer Van Hook. (2010). Trajectories of overweight among US school children: A focus on social and economic characteristics, Maternal and Child Health Journal 15, 610-619.

Bandura, A. (1977). Self-efficacy: toward a unifying theory of behavioral change, Psychological review, 84(2), 191.

Bandura, A. (1993). Perceived self-efficacy in cognitive development and functioning, Educational Psychologist 28, 117-148.

Bandura, A. (1994). Self-efficacy. Corsini Encyclopedia of Psychology 1-3.

Bandura, A. (2005). The primacy of self-regulation in health promotion. Applied Psychology, 54(2), 245-254.

Bandura, A. (2006). Self-efficacy Beliefs in Adolescents. Pajares, F. and T.C. Irdan (eds). IAPInformation Age Publishing.

Baskin, M.L., Ard, J., Franlkin, F., and D.B. Allison. (2005). Prevalence of obesity in the United States, Obesity Reiew 6: 5-7. 
Self-efficacy, Weight, and Children's Math Achievement

Befort, C.A. Nazir, N., and M.G. Perri. (2012). Prevalence of obesity among adults from rural and urban areas of the United States: Findings from NHANES (2005-2008), Journal of Rural Health 28, 392-7.

Braet, C., Claus, L., S., Verbeken, and L. van Vlierberghe. (2007). Impulsivity in overweight Children, European Child and Adolescent Psychiatry 16(8), 473-483.

Brown, S. D., Lent, R. W., \& Larkin, K. C. (1989). Self-efficacy as a moderator of scholastic aptitude-academic performance relationships. Journal of vocational behavior, 35(1), 6475.

Brownwell, K. and K.B. Horgen. (2004). Food fight: The inside story of the food industry, America's obesity crisis, and what we can do about it. McGraw Hill: New York.

Casey, B. J., Tottenham, N., Liston, C., \& Durston, S. (2005). Imaging the developing brain: what have we learned about cognitive development? Trends in cognitive sciences, 9(3), 104-110.

Chi, S. H., Grigsby-Toussaint, D.S., Bradford, N., and J. Choi. (2013). Can geographically weighted regression improve our contextual understanding of obesity in the US? Findings from the USDA Food Atlas, Applied Geography 44, 134-42.

Clark, M. M., Abrams, D. B., Niaura, R. S., Eaton, C. A., \& Rossi, J. S. (1991). Self-efficacy in weight management, Journal of consulting and clinical psychology, 59(5), 739.

Cowen, E. L., Work, W. C., Hightower, A. D., Wyman, P. A., Parker, G. R., \& Lotyczewski, B. S. (1991). Toward the development of a measure of perceived self-efficacy in children, Journal of Clinical Child and Adolescent Psychology, 20(2), 169-178.

Crandall, Christian and Kristin Schiffhauer. (1998). Anti Fat Prejudice: Beliefs, Values, and American Culture, Obesity Research 6, 458-60.

Crisp, A.H. and B. McGuiness. (1976). Jolly fat: relation between obesity and psychoneurosis in general population, British Medical Journal 1, 7-9.

Crosnoe, Robert. (2007). Gender, Obesity, and Education, Sociology of Education 80, 241260.

Cserjesi, R., Luminet, O., Molnar, D., and L. Lenard. (2007). Is there a relationship between obesity and mental flexibility in children?, Appetite 49, 675-678.

Currie, J. (2009). Healthy, Wealthy, and Wise: Socioeconomic status, poor health in childhood, and human capital development. Journal of. Economic Literature., American Economic Association 47(1), 87-122. 
Self-efficacy, Weight, and Children's Math Achievement

Daniels SR, Arnett DK, Eckel RH, et al. (2005). Overweight in children and adolescents: pathophysiology, consequences, prevention, and treatment, Circulation 111, 19992002.

Dannefer, D. (1984). Adult development and social theory: A paradigmatic reappraisal, American Sociological Review 49(1), 100-116.

Davis, C.L., Tomporowski, P.D., McDowell, J.E., Austin, B.P., Miller, P.H., Tanasak, N.E., Allison, J.D., and J.A. Naglieri. (2011). Exercise improves executive function and achievement and alters brain activation in overweight children: A randomized, controlled trial, Healthy Psychology 30(1), 91-98.

Desforges, Charles, and Alberto Abouchaar. (2003). The impact of parental involvement, parental support and family education on pupil achievement and adjustment: A review of literature. London: DFES Publications.

Dietz, W. H. (1998). Health consequences of obesity in youth: childhood predictors of adult disease. Pediatrics, 101(Supplement 2), 518-525.

Dubow, E.F., Boxer, P., and Huesmann, L.R. (2010). Long-term effects of Parents' Education on Children's Educational and Occupational Success: Mediation by Family Interactions, Child Aggression, and Teenage Aspirations, Merril-Palmer Quarterly 55(3), 224-249.

Frankl, V. E. (1963). Man’s search for meaning. Boston: Beacon Press.

Fredrickson, B. L., Roberts, T. A., Noll, S. M., Quinn, D. M., \& Twenge, J. M. (1998). The swimsuit becomes you: Sex differences in self-objectification, restrained eating, and math performance. Journal of Personality and Social Psychology, 75, 269-284.

Freedman DS, Zuguo M, Srinivasan SR, Berenson GS, Dietz WH. (2007). Cardiovascular risk factors and excess adiposity among overweight children and adolescents: the Bogalusa Heart Study, Journal of Pediatrics 150(1), 12-17.

Gable, Sara, Krull, Jennifer L., and Yiting Chang. (2012). Boys' and girls' weight status and math performance from kindergarten entry through fifth grade: A mediated analysis, Child Development 83(5), 1822-1839.

Garver, W.S., Newman, S.B., Gonzales-Pacheo, D.M., Castillo, J.J., Jelinke, D., Heidenreich, R.A., and R.A. Orlando. (2013). The genetics of childhood obesity and interaction with dietary macronutrients, Genes and Nutrition 8, 271-287.

Hulst, A.V. Gauvin, L. Kestens Y., and T.A. Barnett. (2013). Neighborhood built and social environment characteristics: a multilevel analysis of associations with obesity among children and their parents, International Journal of Obesity 37, 1328-35. 
Self-efficacy, Weight, and Children’s Math Achievement

Judge, S., \& Jahns, L. (2007). Association of overweight with academic performance and social and behavioral problems: an update from the early childhood longitudinal study. Journal of School Health, 77(10), 672-678.

Johnston, W. A., \& Heinz, S. P. (1978). The flexibility and capacity demands of attention. Journal of Experimental Psychology: General, 707, 420-435.

Klinitzke, G., Steinig, J., Bluher, M., Kersting, A., and B. Wagner. (2012). Obesity and suicide risk in adults-A systemic review, Journal of Affective Disorders 145, 277-284.

Kaestner, R. Grossman, M., and B. Yarnoff. (2009). Effects of weight n adolescent educational attainment, NBER Working Paper: National Bureau of Economic Research.

Kolb, D. A. (1984). Experiential learning: Experience as the source of learning and development (Vol. 1). Englewood Cliffs, NJ: Prentice-Hall.

Li, Y., Dai, Q., Jackson, J. C., \& Zhang, J. (2008). Overweight is associated with decreased cognitive functioning among school-age children and adolescents, Obesity 16(8), 18091815.

Linde, J. A., Rothman, A. J., Baldwin, A. S., \& Jeffery, R. W. (2006). The impact of selfefficacy on behavior change and weight change among overweight participants in a weight loss trial, Health Psychology, 25(3), 282.

Finkelstein, J E.A., Trogdon, J.G., Cohen, J.W., and W. Dietz. (2009). Annual medical spending attributable to obesity: payer- and service-specific estimates, Health Affairs 28, w822-w831.

Fredrickson, B. L., Roberts, T. A., Noll, S. M., Quinn, D. M., and J. M. Twenge. (1998). The swimsuit becomes you: Sex differences in self-objectification, restrained eating, and math performance, Journal of Personality and Social Psychology 75, 269-284.

Frisco, M.L., Houle, J.N., and M.A. Martin. (2010). The image in the mirror and the number on the scale: Weight perceptions and adolescents depressive symptoms, Journal of Health and Social Behavior 51(2), 215-228.

Giskes, K., van Lenthe, F.J., Turrell, G., Kamphuis, C.B., and J. Brug. (2008). Socioeconomic position at different srages of the life course and its influence on body weight and weight gain in adulthood: A longitudinal study with 13-year follow up, Obesity 16(6), 13771381.

Gopal K. Singh; Michael D. Kogan; Peter C. van Dyck. (2010). Changes in State-Specific Childhood Obesity and Overweight Prevalence in the United States From 2003 to 2007, Archives of Pediatrics \& Adolescent Medicine 84. 
Self-efficacy, Weight, and Children’s Math Achievement

Hedley, A.A., Ogden, C.L., Johnson C.L., Carroll, M.D., Curtin, L.R., and K.M. Flegal. (2004). Prevalence of overweight and obesity among US children, adolescents, and adults, 19992002, Journal of American Medical Association 291, 2847-50.

Judge, Timothy A., Erez, Amir, Bono, Joyce E., and Carl J. Thoresen. (2002). Are measures of self-esteem, neuroticism, locus of control, and generalized self-efficacy indicators of a common core construct? Journal of Personality and Social Psychology 83(3), 693-710.

Kamijo, K., Pontifex, M.B., Khan, N.A., Raine, L.B., Scudder, M.R., Drollette, E.S., Evans, E.M., Castello, D.M., and C.H. Hillman. (2014). The Negative Association of Childhood Obesity to Cognitive Control of Action Monitoring, Cerebral Cortex 24, 654-662.

Kopelman, P. (2007). Health risks associated with overweight and obesity, Obesity Review 8, 13-7.

Kuczmarski, R.J., Ogden, C.L., Guo, S.S., Grummer Strawn, L., Felgal, M., and S.Mei et al. (2002). 2000 CDC growth charts for the United States: Methods and development. National Center for Health Statistics, Vital Health Statistics 11, 246.

Li, Y., Dai, Q., Jackson, J., \& Zhang, J. (2008) Overweight is associated with decreased cognitive functioning among school-age children and adolescents, Obesity, 16, 1809 -1815 .

Linde, J. A., Rothman, A. J., Baldwin, A. S., \& Jeffery, R. W. (2006). The impact of selfefficacy on behavior change and weight change among overweight participants in a weight loss trial. Health Psychology, 25(3), 282.

Ludwig, D. S. (2007). Childhood obesity - the shape of things to come. New England Journal of Medicine, 357(23), 2325-2327.

McLaren, L. (2007). Socioeconomic status and obesity, Epidemiological Review 29, $29-48$.

Markon, K.E., Chmielewski, M., and C.J. Miller. (2011). The reliability and validity of discrete and continuous measures of psychopathology: A quantitative review, Psychological Bulletin 137, 856-879.

Marlow, M.L. (2013). Determinants of state laws addressing obesity, Applied Economic Letters.21, 84-9.

McCabe, M. P., \& Ricciardelli, L. A. (2005). A longitudinal study of body image and strategies to lose weight and increase muscles among children, Applied Developmental Psychology 26, 559-577.

Multon, K. D., Brown, S. D., \& Lent, R. W. (1991). Relation of self-efficacy beliefs to academic outcomes: A meta-analytic investigation. Journal of counseling psychology, 38(1), 30. 
Self-efficacy, Weight, and Children’s Math Achievement

OECD; Organization for Economic Cooperation and Development (2013), Education at a Glance 2013: OECD Indicators, OECD Publishing. http://dx.doi.org/10.1787/eag-2013-en.

Ogden, C.L., Carroll, M.D., Kit, B.K., and K.M. Flegal. (2014). Prevalence of childhood obesity in the United States, 2011-2012. Journal of the American Medical Association, 311(8), 806-14.

Ogden, C.L., Carroll, M.D., Kit, B.K., and K.M. Flegal. (2012). Prevalence of childhood obesity in the United States, 1999-2010. Journal of the American Medical Association, 307(5), 806-14.

Pajares, F., \& Miller, M.D. (1994). Role of self-efficacy and self-concept beliefs in mathematical problemsolving: A path analysis. Journal of educational psychology, 86(2), 193.

Pajares, F., \& Kranzler, J. (1995). Self-efficacy beliefs and general mental ability in mathematical problem-solving. Contemporary Educational Psychology, 20, 426-443.

Power, C., Manor, O., and S. Matthew. (2003). Child to adult socioeconomic conditions and obesity in a national cohort. International Journal of Obesity and Related Metabolic Disorders, 27(9), 1081-1086.

Robinson, S. (2006). Victimization of obese adolescents. The Journal of school nursing, 22(4), 201-206.

Scott, K.M., Bruffaerts, R., Simon, G.E., Alonso, J., Angermeyer, M., de Girolamo, Demyttenaere, G. K., Gasquet, I., Haro, J.M., Karam, E., Kessler, R.C., Levinson, D., Mora, M.E.M., Browne, M.A. O., Ormel, Villa, J. J.P., Uda, H., and M. Von Korff. (2008). Obesity and mental disorders in the general population: results from the world mental health surveys, International Journal of Obesity 32, 192-200.

Schunk, D. H. (1995). Self-efficacy and education and instruction. In Self-efficacy, adaptation, and adjustment pp. 281-303, Springer US.

Schunk, D. H., \& Pajares, F. (2004). Self-efficacy in Education revisited. Big theories revisited, 15-138.

Seligman, M. E. P. (1998). Learned optimism: How to change your mind and your life (2nd ed.). New York: Pocket Books.

Shore, S., Sachs, M., Lidicker, J., Brett, S., Wright, A., \& Libonati, J. (2008). Decreased scholastic achievement in overweight middle school students. Obesity, 16, 1535-15.

Siegel, R. G., Galassi, J. P., \& Ware, W. B. (1985). A comparison of two models for predicting mathematics performance: Social learning versus math aptitude-anxiety. Journal of Counseling Psychology, 32(4), 531. 
Self-efficacy, Weight, and Children's Math Achievement

Singer, J. D., and J. B. Willett. (2003). Applied longitudinal analysis. Modeling change and event occurrence. New York: Oxford University Press.

St Clair-Thompson, H.L. and S.E. Gathercole. (2006). Executive functions and achievements in school: Shifting, updating, inhibition, and working memory. The Quarterly Journal of Experimental Psychology 59(4), 745-59.

Strauss, R.S. and H.A. Pollack. (2003). Social marginalization of overweight children. Archives of Pediatric and Adolescent Medicine, 157(8), 746-752.

Taras, H., \& Potts-Datema, W. (2005). Obesity and student performance at school. Journal of School Health, 75(8), 291-295.

Taylor, S. E. (1989). Positive illusions: Creative self-deception and the healthy mind. New York: Basic Books.

Taylor, S. E., Kemeny, M. E., Reed, G. M., Bower, J. E., \& Gruenewald, T. L. (2000).

Psychological resources, positive illusions, and health. American psychologist, 55(1), 99.

Tershakovec, A.M. Weller, S.C., and P.R. Gallagher. (1994). Obesity, school performance and behavior of black, urban elementary school children. International Journal of Obesity and Related Metabolic Disorders, 18(5), 232-7.

Tomporowski, P.D., Davis, C.L., Miller, P.H., and J.A. Nagliri. (2008). Exercise and children's intelligence, cognition, and academic achievement, Education Psychology Review 20, 111-131.

Tourangeau, K., Nord, C., Lê, T., Sorongon, A. G., and Najarian, M. (2009). Early Childhood Longitudinal Study, Kindergarten Class of 1998-99 (ECLS-K), Combined User's Manual for the ECLS-K Eighth-Grade and K-8 Full Sample Data Files and Electronic Codebooks (NCES 2009-004). National Center for Education Statistics, Institute of Education Sciences, U.S. Department of Education. Washington, DC.

United States Census Bureau. (2013). Accessed April 5, 2014 at http://www.census.gov/population/intmigration.

Wadden, T.A., Foster, G.D., Stunkard, A.J., and J.R. Linowitz. (1989). Dissatisfaction with weight and figure in obese girls: discontent but not depression, International Journal of Obesity 13, 89-97.

Wang, J., Sereika, S.M., Styn, M.A., and L.E. Burke. (2013). Factors associated with healthrelated quality of life among overweight or obese adults, Journal of Clinical Nursing 22, 2172-82.

West, J., Denton, K., Reaney, L. M., Campbell, J. R., Hombo, C. M., Mazzeo, J., ... \& Angeles, 
Self-efficacy, Weight, and Children's Math Achievement

J. (2000). Kindergarten. National Center for Education Statistics, 2(4), 25.

Woolf, S. H., and Aron, L. (Eds.). (2013). US Health in International Perspective: Shorter Lives, Poorer Health. National Academies Press.

Woodcock, R. W., McGrew, K. S., and J. K. Werder. (1996). Woodcock-McGrew-Werder MiniBattery of Achievement. Itasca, IL: Riverside.

Yanovski, S.Z. and J.A. Yanovski. (2011). Obesity prevalence in the United States - Up, down, or sideways? New England Journal of Medicine 364, 987-9.

Zametkin AJ, Zoon CK, Klein HW, Munson S. (2004). Psychiatric aspects of child and adolescent obesity: a review of the past 10 years. Journal of American Academy of Child Adolescent Psychiatry, 43(2), 134- 1 SO.

Zimmerman, B. J. (1989). A social cognitive view of self-regulated academic learning. Journal of educational psychology, 81(3), 329.

Zimmerman, B. J. (2000). Self-efficacy: An essential motive to learn. Contemporary educational psychology, 25(1), 82-91. 
Self-efficacy, Weight, and Children's Math Achievement

Table 1: Means and Standard Deviations for Time Varying Covariates, by Wave

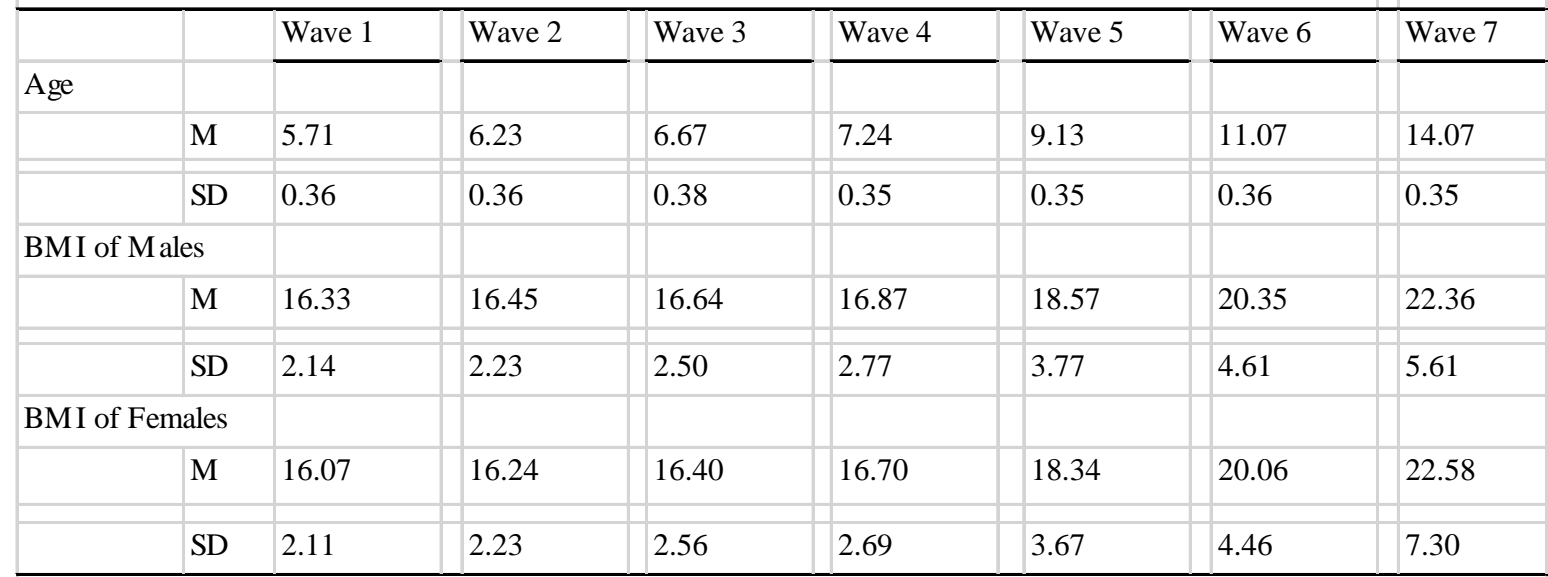

Source: Data are from the Early Childhood Longitudinal Study Kindergarten Class 1998-1999. 
Self-efficacy, Weight, and Children's Math Achievement

Table 2. Weighted Means and S tandard Errors for Time Invariant

Covariates, by Weight $S$ tatus

\begin{tabular}{|c|c|c|c|c|c|c|}
\hline \multirow[b]{2}{*}{ Variable } & \multicolumn{2}{|c|}{ Normal-weight } & \multicolumn{2}{|c|}{ Overweight } & \multicolumn{2}{|c|}{ Obese } \\
\hline & $\mathrm{M}$ & (SE) & $\mathrm{M}$ & (SE) & $\mathrm{M}$ & (SE) \\
\hline \multicolumn{7}{|l|}{ Demograhics } \\
\hline \multicolumn{7}{|l|}{ Gender } \\
\hline Male & 0.52 & $(0.01)$ & 0.53 & $(0.02)$ & 0.61 & $(0.02)$ \\
\hline Female & 0.48 & $(0.01)$ & 0.47 & $(0.02)$ & 0.39 & $(0.02)$ \\
\hline \multicolumn{7}{|l|}{ Race/ethnicity } \\
\hline White & 0.75 & $(0.02)$ & 0.69 & $(0.03)$ & 0.63 & $(0.03)$ \\
\hline African American & 0.04 & $(0.01)$ & 0.06 & $(0.01)$ & 0.06 & $(0.01)$ \\
\hline Hispanic & 0.15 & $(0.01)$ & 0.19 & $(0.03)$ & 0.24 & $(0.02)$ \\
\hline Asian & 0.03 & $(0.01)$ & 0.02 & $(0.01)$ & 0.02 & $(0.01)$ \\
\hline Other Race & 0.04 & $(0.01)$ & 0.04 & $(0.01)$ & 0.05 & $(0.01)$ \\
\hline \multicolumn{7}{|l|}{ Self-efficacy } \\
\hline Low & 0.47 & $(0.01)$ & 0.48 & $(0.02)$ & 0.53 & $(0.01)$ \\
\hline High & 0.53 & $(0.01)$ & 0.52 & $(0.02)$ & 0.47 & $(0.01)$ \\
\hline \multicolumn{7}{|l|}{ Parent Education Level } \\
\hline Highschool Drop out & 0.03 & $(0.01)$ & 0.08 & $(0.02)$ & 0.08 & $(0.01)$ \\
\hline Highschool Graduate & 0.13 & $(0.01)$ & 0.16 & $(0.01)$ & 0.21 & $(0.02)$ \\
\hline Some College & 0.05 & $(0.01)$ & 0.06 & $(0.01)$ & 0.08 & $(0.01)$ \\
\hline College Graduate & 0.26 & $(0.01)$ & 0.21 & $(0.02)$ & 0.02 & $(0.01)$ \\
\hline Advanced Degree & 0.27 & $(0.01)$ & 0.21 & $(0.02)$ & 0.15 & $(0.01)$ \\
\hline $\mathbf{N}$ & 3,090 & 3090 & 1,061 & & 922 & \\
\hline \multicolumn{7}{|c|}{ Source: Data are for children from 1998-2007 ECLS-K } \\
\hline \multicolumn{3}{|c|}{ Note: SE indicates Standard Error } & & & & \\
\hline
\end{tabular}


Self-efficacy, Weight, and Children's Math Achievement

Table 3. Estimated Coefficients for Quadratic Growth Model of

\begin{tabular}{|l|l|l|l|l|}
\hline Math Achievement Scores & & & \\
\hline Fixed Effects & Coefficient & SE & t ratio & $p$ \\
\hline Intercept, $\pi 0 \mathrm{i}$ & 17.19 & 0.15 & 116.75 & $<0.001$ \\
\hline Age, $\pi 1 \mathrm{i}$ & 29.87 & 0.07 & 455.06 & $<0.001$ \\
\hline Age2, $\pi 2 \mathrm{i}$ & -1.61 & 0.01 & -266.32 & $<0.001$ \\
\hline & & & & \\
\hline Random Effects & Variance Com $\mathrm{df}$ & $\chi 2$ & $\mathrm{p}$ \\
\hline Level 1 & & & & \\
\hline$\varepsilon_{\text {it }}$ & 6.01 & & & \\
\hline Level 2 & & & & \\
\hline Intercept, $\pi 0 \mathrm{i}$ & 7.57 & 4925 & $10,257.73$ & $<0.001$ \\
\hline Age, $\pi 1 \mathrm{i}$ & 2.9 & 4925 & $7,217.56$ & $<0.001$ \\
\hline Age2, $\pi 2 \mathrm{i}$ & 0.24 & 4925 & $5,692.63$ & $<0.001$ \\
\hline Source: Data & for & & & \\
\hline
\end{tabular}

Source: Data are for children between 1998-2007, ECLS-K.

Note: SE indicates Standard Error 
Self-efficacy, Weight, and Children's Math Achievement

Table 4. Estimated Coefficients for Quadratic Growth Model of Math

Achievement S cores with Time-varying Indicator of Weight Status

\begin{tabular}{|l|l|l|l|l|}
\hline Fixed Effects & Coefficient & SE & t ratio & $p$ \\
\hline Intercept, $\pi 0 \mathrm{i}$ & 14.8 & 0.25 & 58.41 & $<0.001$ \\
\hline Age, $\pi 1 \mathrm{i}$ & 29.74 & 0.07 & 449.2 & $<0.001$ \\
\hline Age2, $\pi 2 \mathrm{i}$ & -1.60 & 0.01 & -262.54 & $<0.001$ \\
\hline BMI, $\pi 3 \mathrm{i}$ & -0.0001 & 0.00 & -26.41 & $<0.001$ \\
\hline Overweight, $\pi 4 \mathrm{i}$ & -5.77 & 0.07 & -8.46 & $<0.001$ \\
\hline Obesity, $\pi 5 \mathrm{i}$ & -7.97 & 0.69 & -11.59 & $<0.001$ \\
\hline Random Effects & Variance Com df & $\chi 2$ & $\mathrm{p}$ \\
\hline Level 1 & & & & \\
\hline$\varepsilon_{\text {it }}$ & 35.66 & & & \\
\hline Level 2 & & & & \\
\hline Intercept, $\pi 0 \mathrm{i}$ & 34.85 & 4925 & $7,907.35$ & $<0.001$ \\
\hline Age, $\pi 1 \mathrm{i}$ & 8.81 & 4925 & $7,326.05$ & $<0.001$ \\
\hline Age2, $\pi 2 \mathrm{i}$ & 0.06 & 4925 & $5,781.46$ & $<0.001$ \\
\hline BMI, $\pi 3 \mathrm{i}$ & 0.25 & 4925 & 485.70 & 0.01 \\
\hline Overweight, $\pi 4 \mathrm{i}$ & 0.33 & 4925 & 488.20 & 0.03 \\
\hline Obesity, $\pi 5 \mathrm{i}$ & 0.21 & 4925 & 453.60 & 0.02 \\
\hline Source: Data are for children between 1998 & -2007, ECLS-K. \\
\hline Note: SE indicates Standard Error & & \\
\hline
\end{tabular}


Self-efficacy, Weight, and Children's Math Achievement

Table 5. Estimated Effects of Self-efficacy on Math

Achievement for Overweight and Obese

Children by Selected Characteristics

\begin{tabular}{|c|c|c|c|}
\hline & $\mathrm{BMI}$ & Overweight & Obese \\
\hline Intercept & $-0.0002^{* * *}$ & $-6.61 * * *$ & $-7.21 * * *$ \\
\hline \multicolumn{4}{|l|}{ Child Variables } \\
\hline Female & $-0.00002 * * *$ & 1.09 & -0.0003 \\
\hline SE & 0.000004 & 1.20 & 1.32 \\
\hline \multicolumn{4}{|l|}{ Race } \\
\hline African American & $-0.000006^{* * *}$ & -5.82 & -0.87 \\
\hline SE & 0.00001 & 5.12 & 2.46 \\
\hline Hispanic & $-0.00001^{*}$ & -2.90 & -2.53 \\
\hline SE & 0.000005 & 2.48 & 2.94 \\
\hline Asian & 0.00002 & 3.62 & 5.09 \\
\hline SE & 0.00001 & 2.49 & 2.99 \\
\hline Other & 0.000004 & -1.72 & -7.88 \\
\hline SE & 0.000007 & 2.59 & 3.25 \\
\hline \multicolumn{4}{|c|}{ Child Characteristics } \\
\hline High Self-efficacy & 0.000001 & $3.62 * *$ & 0.43 \\
\hline SE & 0.000002 & 1.26 & 1.25 \\
\hline \multicolumn{4}{|c|}{ Family Charcateristics } \\
\hline HS Graduate & -0.00001 & -1.36 & -2.69 \\
\hline SE & 0.00008 & 2.07 & 1.91 \\
\hline Some College & -0.00002 & $-6.23 * *$ & -3.68 \\
\hline SE & 0.00001 & 2.84 & 2.52 \\
\hline College Graduate & $0.00002 * * *$ & $3.79 *$ & 0.60 \\
\hline SE & 0.000006 & 1.75 & 1.77 \\
\hline Advanced Degree & $0.00003^{* * *}$ & $4.68 * *$ & 1.87 \\
\hline SE & 0.000005 & 1.62 & 1.72 \\
\hline \multicolumn{4}{|c|}{ Source: Data are from the ECLS-K (1998-1999). } \\
\hline \multicolumn{4}{|c|}{ Note: SE indicates Standard Error. } \\
\hline \multicolumn{3}{|c|}{ Note: $* \mathrm{p}<0.05 * * \mathrm{p}<0.005 * * * \mathrm{p}<0.001$} & \\
\hline
\end{tabular}


Self-efficacy, Weight, and Children's Math Achievement

Figure 1: Effect of Age and High Self-efficacy on Math Achievement, by Weight Status

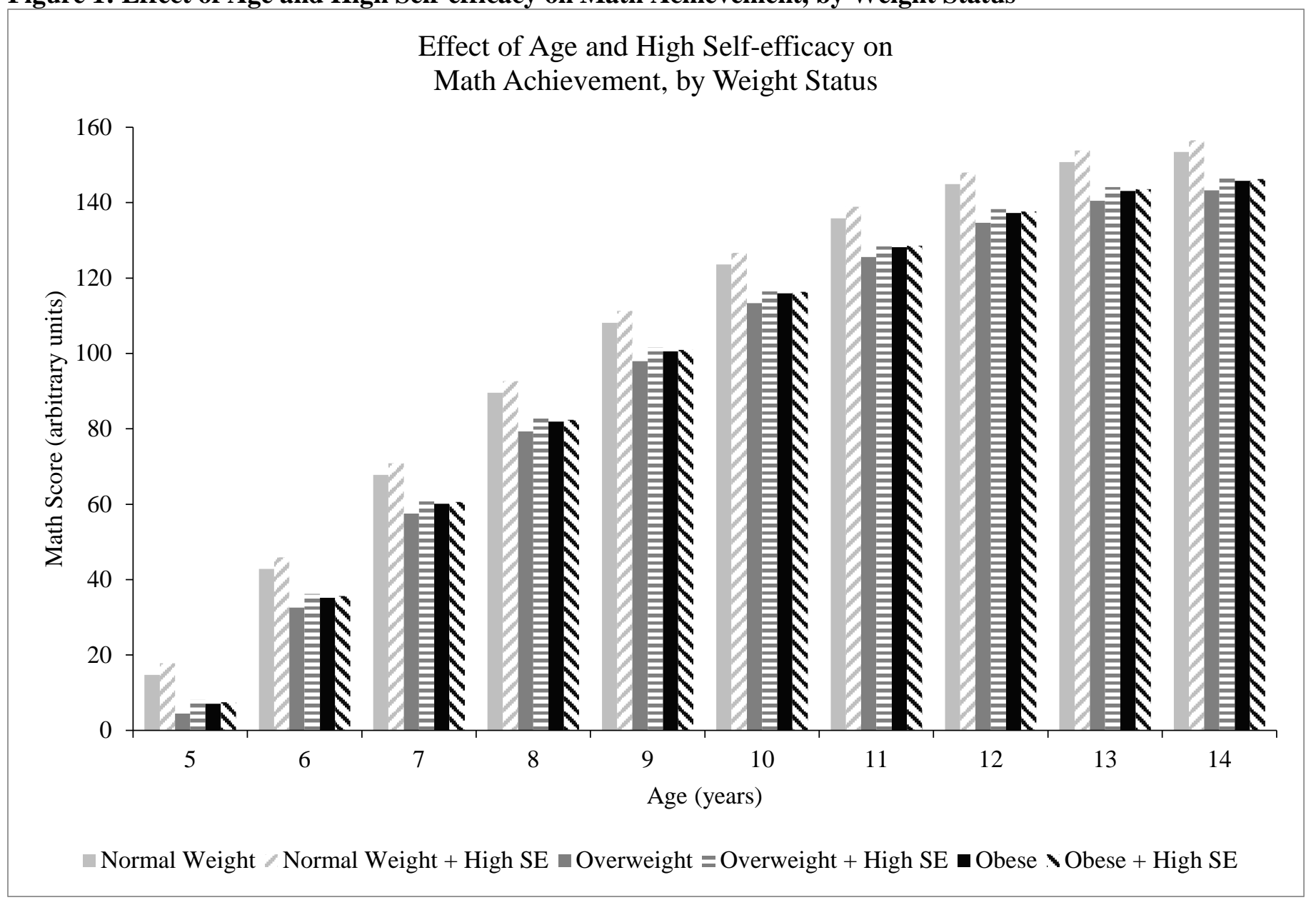

